\title{
Trypsin dose optimization for glaucoma induction in rabbit model
}

\author{
N.M. Muharib $\mathbb{D}^{\circ}$ and H.A. Al- Timmemi \\ Department of Surgery and Obstetrics, College of Veterinary Medicine, University of Baghdad, Baghdad, Iraq
}

\begin{tabular}{l} 
Article information \\
\hline Article history: \\
Received October 11, 2021 \\
Accepted November 06, 2021 \\
Available online December 11, 2021 \\
\hline Keywords: \\
Glaucoma \\
Rabbit \\
Trypsin \\
Retinal ganglionic cells \\
Optic nerve \\
\hline Correspondence: \\
N.M. Muharib \\
nour.muharib93@ gmail.com
\end{tabular}

\begin{abstract}
Glaucoma is a neurodegenerative disease identified by optic nerve damage and loss of retinal ganglionic cells. The aim of the study was to test the precise dose of trypsin to induce glaucoma in a rabbit model. Nine White New Zealand rabbits were randomly divided into three groups: Group one (G1) normal animals as control, group two (G2) the animals were injected with $0.2 \mathrm{ml}$ of $0.04 \%$ trypsin and group three (G3) injected with $0.2 \mathrm{ml}$ of $0.05 \%$ trypsin into posterior chamber of eye. A schiotz tonometer was used to measure intraocular pressure (IOP) before the injection, two days after injection and once a week until the end of the second week. At the end of the second week, the histology of the retina and optic nerve was studied. G3's intraocular pressure increased by $43.7 \%$, while G2's intraocular pressure increased by $0.7 \%$ compared to G1. Retinal ganglionic cells (RGCs) decreased in G3 by $91.5 \%$ and G2 by $43.8 \%$ in comparison with G1. Optic nerve histology in G3 displayed decreased Schwann cell quantity with vacuolation and low orientation of nerve fibers compared with G1 and G2. Group three had the highest increase in IOP due to obstruction of drainage canal and preventing outflow of aqueous humor. This resulted in mechanical compression on the retina, ending with loss of RGC and degeneration of the optic nerve. The conclusion is that $0.2 \mathrm{ml}$ of $0.05 \%$ trypsin is the proper dose for the induction of glaucoma.
\end{abstract}

DOI: 10.33899/ijvs.2021.131748.2001, (A)Athors, 2021, College of Veterinary Medicine, University of Mosul.

This is an open access article under the CC BY 4.0 license (http://creativecommons.org/licenses/by/4.0/).

\section{Introduction}

Glaucoma is a neurodegenerative disease identified by optic nerve damage and loss of retinal ganglionic cells (1). The most common risk factor of glaucoma is increased intraocular pressure (2). Rabbit is the proper model for study pharmacokinetic therapies of eye diseases furthermore the adequate size of eye ball that create easy handling (3). Glaucoma was induced by different methods and different models. (4) demonstrated that cauterization of episcleral vein in mouse model the intraocular pressure was increased until fourth week but this method may associate with burns of the sclera. Hyaluronic acid was injected into the anterior chamber in rat model the intraocular pressure increased up to 8 days with repeated injections the elevation of intraocular pressure extended to 10 weeks this technique may produce corneal problems due to the injection side effect (5). Laser photocoagulation was used for induction of glaucoma in monkey and this produced elevation of intra ocular pressure and changes in the optic nerve and retina but this method is expensive and need special expertise (6). Injection of 150 units of alpha-chemotrypsine into the posterior chamber resulted in increase of intraocular pressure some animals remained with high intraocular pressure till one year but there is no histological study that confirm loss of retinal ganglionic cells (7). In the present study demonstration, the proper dose of trypsin for inducing glaucoma in rabbit model.

\section{Materials and methods}

\section{Experimental animals}

A total of 9 male White New Zealand rabbits, age 4-6 months, weight 1.2-1.8 all rabbits allowed for free access of 
food and water. The animals were randomly divided into three groups $(\mathrm{n}=3)$. Group one $(\mathrm{G} 1)$ normal animals as control. Group two $(\mathrm{G} 2)$ the animals were injected with 0.2 $\mathrm{ml}$ of $0.04 \%$ trypsin. Group three (G3) animals were injected $0.2 \mathrm{ml}$ of $0.05 \%$ trypsin in to the posterior chamber.

\section{Anesthetic protocol}

Animals were anesthetized after intramuscular injection of acepromazine $1 \mathrm{mg} / \mathrm{kg}$ followed after five minutes with xylazine $5 \mathrm{mg} / \mathrm{kg}$ and ketamine $35 \mathrm{mg} / \mathrm{kg}(8)$.

\section{Induction of glaucoma}

Glaucoma was induced by injection of trypsin into posterior chamber with using of 31 gauge syringe (Figure 1). G2 injected with $0.2 \mathrm{ml}$ of $0.04 \%$ trypsin while G3 injected with $0.2 \mathrm{ml}$ of $0.05 \%$ trypsin.

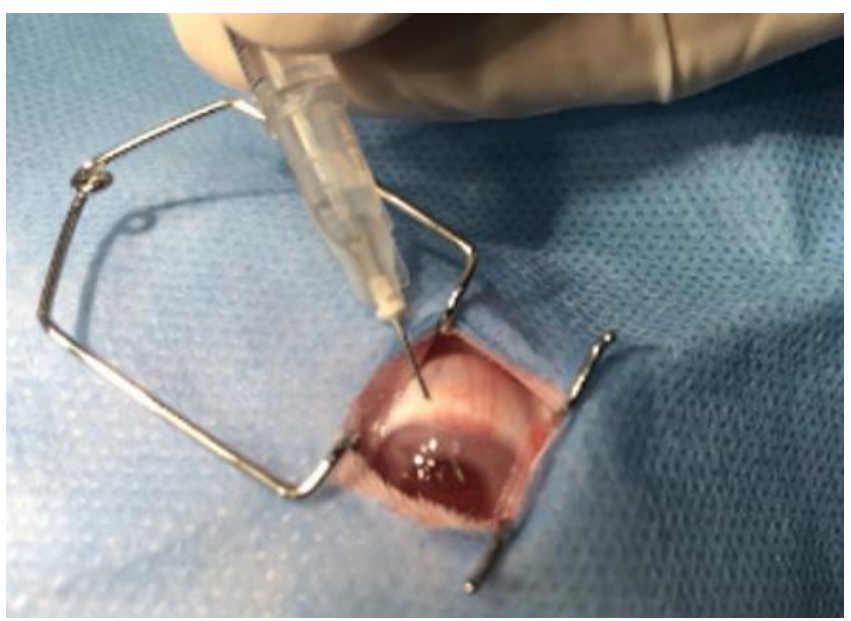

Figure 1: injection of $0.2 \mathrm{ml}$ of trypsin in to posterior chamber for induction of glaucoma

\section{Tonometry}

Intraocular pressure measured before induction, after two days from induction and once weekly until the end of second week with using of schiotz tonometer with $7.5 \mathrm{~g}$ weight after application of local anesthetic eye drop $0.05 \%$ tetracaine.

\section{Histopathology}

Histopathological examination of retina and optic nerve. The eyes were collected after two weeks from induction and fixed in Davidson's solution for 24h then transferred in to different concentrations of alcohol after that processed in paraffin (9). The tissue sectioned in sagittal line at $5 \mu \mathrm{m}$ with microtome. Tissue were stained with hematoxylin and eosin.

\section{Statistical analysis}

Statistical analysis system- SAS program for data analysis to extract the means and SE, One-way ANOVA and Tukey's-b of post hoc test were used for estimate the significant difference of means between groups when $\mathrm{P}<0.05$.

\section{Results}

\section{Clinical Signs}

Clinical signs of the $\mathrm{G} 2$ there was hyperemia of episcleral veins (Figure 2) there was no luxation of lens, no edema of the cornea and no enlargement of the anterior chamber depth (ACD) (Figures 3 and 4). Conversely in G3 there was hyperemia of episcleral veins, enlargements of $\mathrm{ACD}$ in animals (Figures 5 and 6), with extreme elevation of intraocular pressure luxation of lens, edema of cornea in addition to that friable cornea was established in two of three animals in the first seven days after induction (Figure 7 and 8 ). While animals with moderate elevation of intraocular pressure there is no luxation of lens. One animal in the G3 showed cloudy lens this animal was excluded from the experiment.

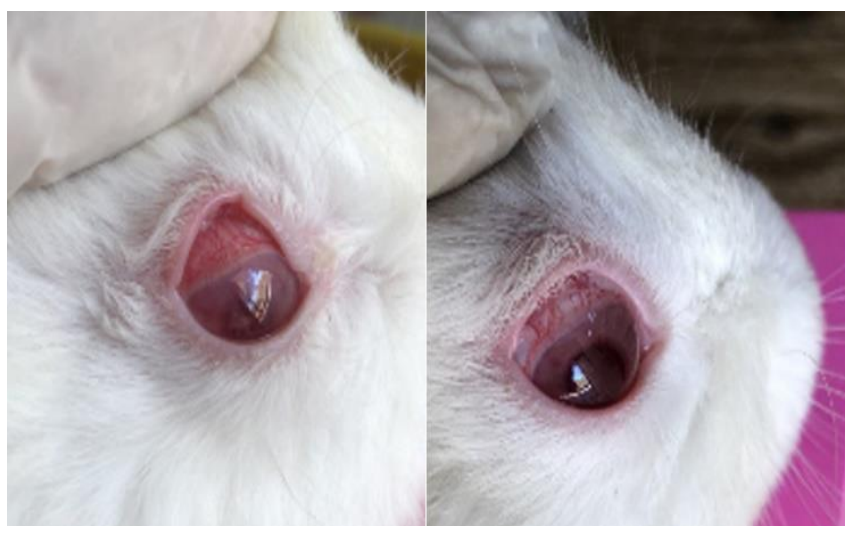

Figure 2: Photographs show hyperemia of episleral veins.

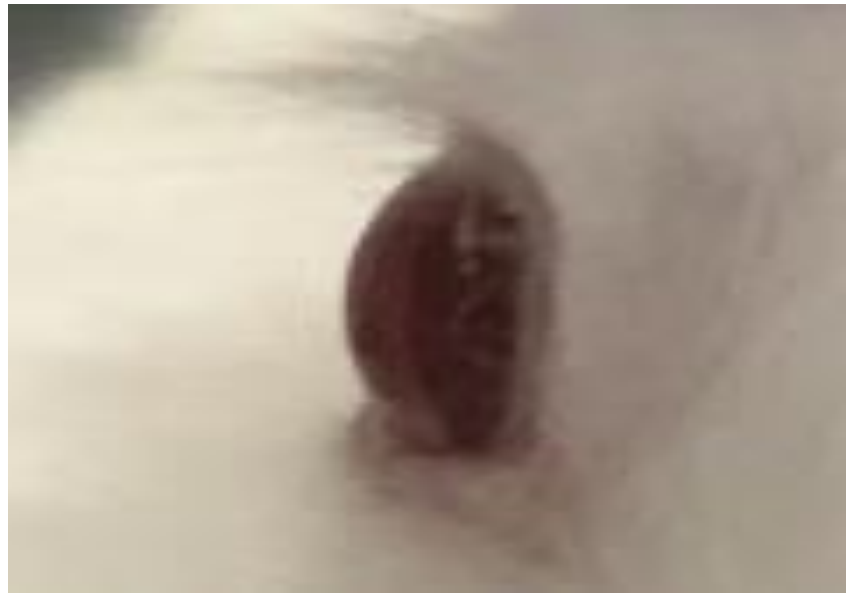

Figure 3: No enlargement of anterior chamber in G2 first week. 


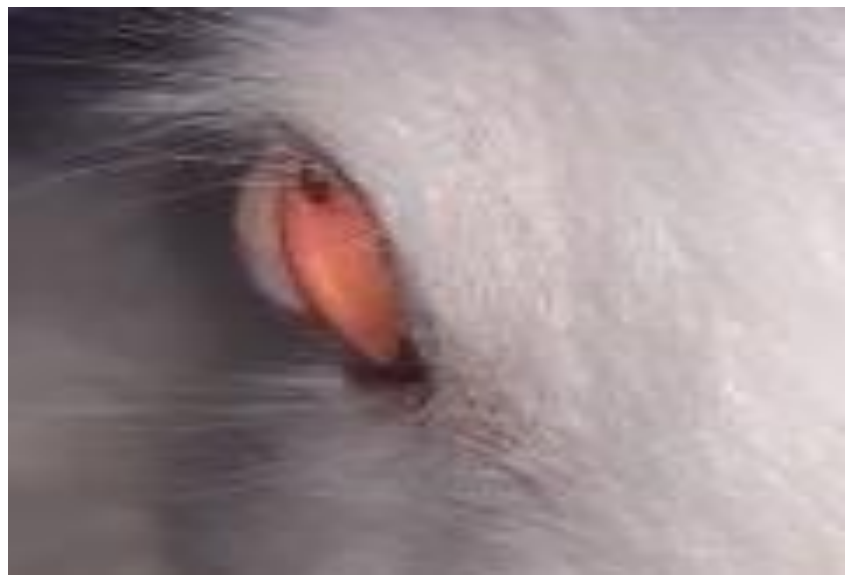

Figure 4: No enlargement of anterior chamber in G2 second week.

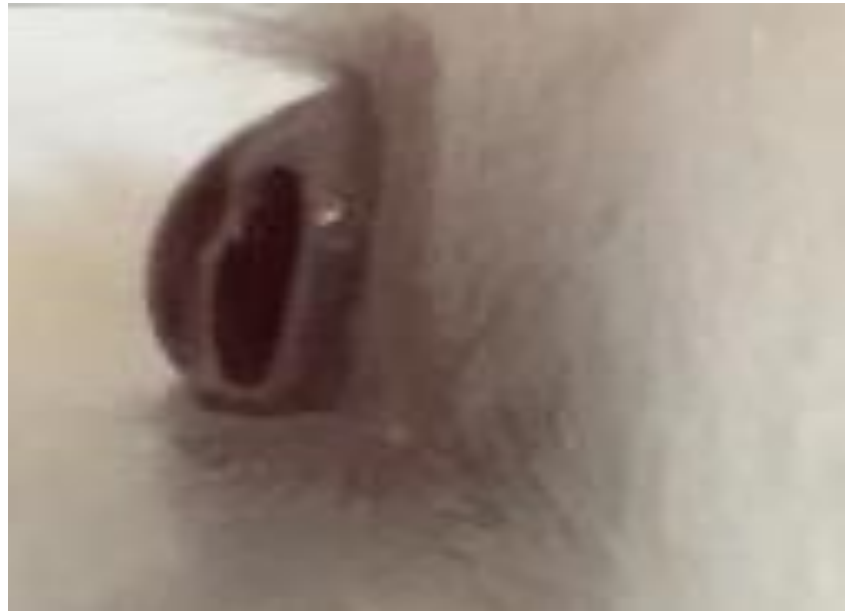

Figure 5: Enlargement of anterior chamber in G3 in the first week after injection.

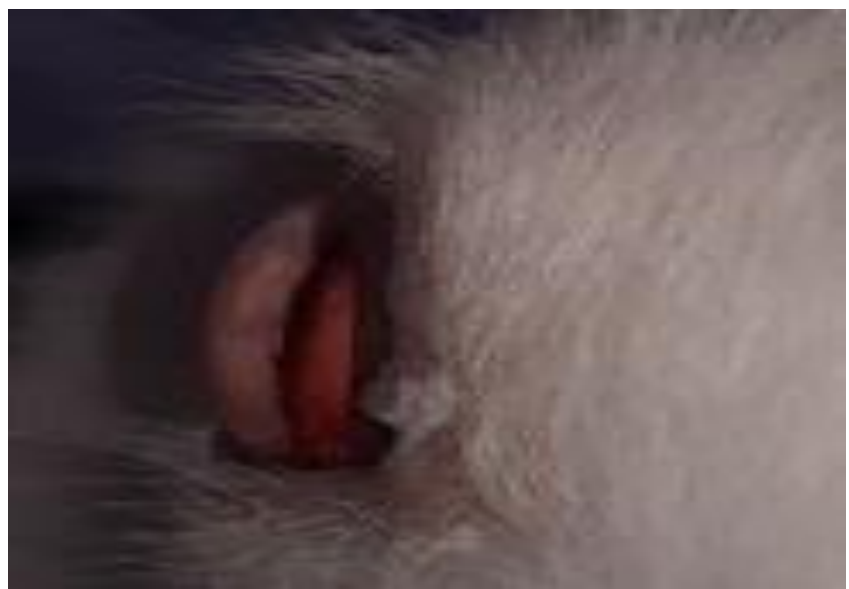

Figure 6: Enlargement of anterior chamber in G3 in the second week after injection.

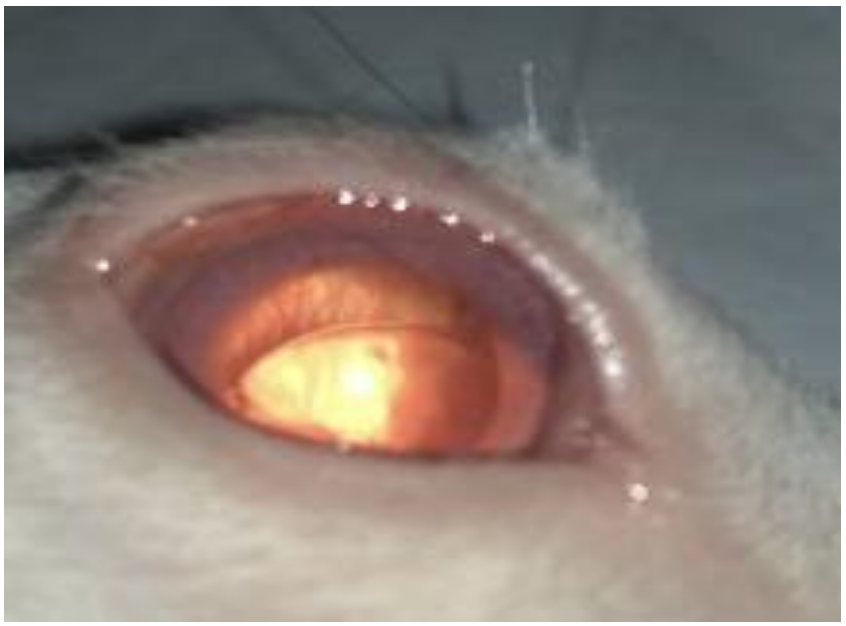

Figure 7: Photographs lateral view show luxation of lens due to extreme elevation of intraocular pressure in animal of G3.

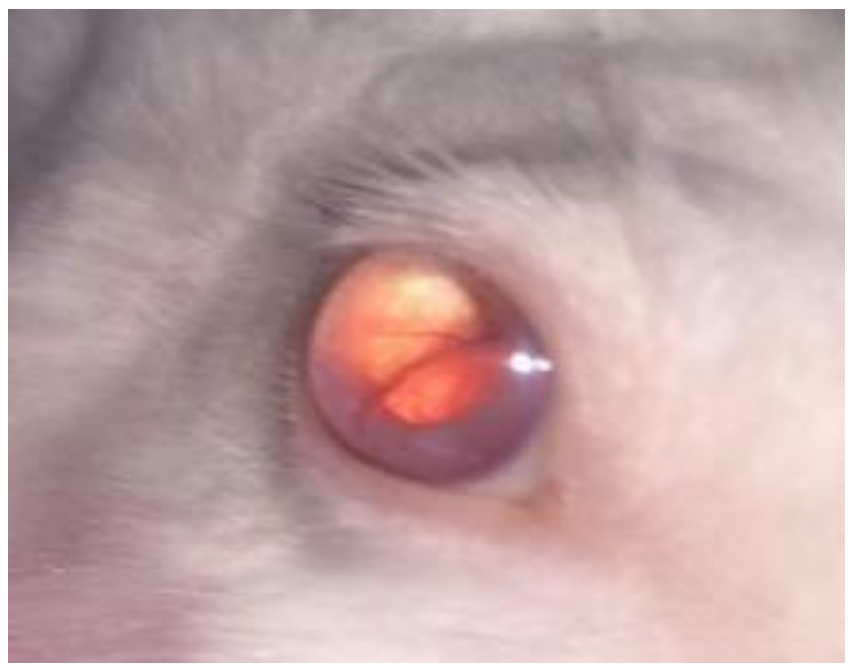

Figure 8: Photographs anterior view show luxation of lens due to extreme elevation of intraocular pressure in animal of G3.

\section{Tonometry}

Intraocular pressure results were increased $0.7 \%$ in $\mathrm{G} 2$ and $43.7 \%$ in G3 in comparison with G1. one of three animals in G2 showed increased IOP it reached to thirties and the other two animals showed the IOP increased but within normal range. In G3 intraocular pressure increased after two days from induction and continued in progressive elevation, intraocular pressure reached to forties. edematous and fragile cornea in the first seven days resulted in false negative recording of intraocular pressure.

The statistical analysis revealed no significant difference between means of IOP in G2 and G1 P > 0.05 in contrast G3 showed significant difference of IOP in compare with G2 and G1 P<0.01 (Table 1, Figure 9). 
Table 1: The means, SE of intraocular pressure

\begin{tabular}{lcc}
\hline Groups & Mean & Std. Error \\
\hline G1 & 25.1333 & 0.66667 \\
G2 & 25.3200 & 2.31035 \\
G3 & $36.0867 *$ & 3.10282 \\
\hline
\end{tabular}

$* \mathrm{P}<0.01$

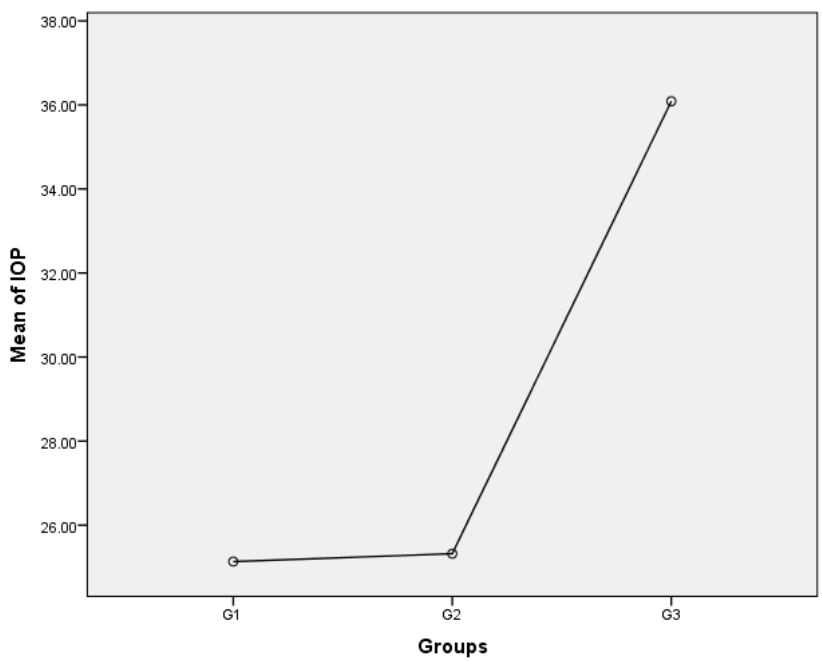

Figure 9: Diagram of means of IOP, G3 had the highest IOP among all groups.

\section{Histopathology \\ Retinal Ganglion Cells}

Histological sections of retina revealed decreased number of retinal ganglion cells $43.8 \%$ in G2and $91.5 \%$ in G3 in comparison with normal animals in G1 (Figures 1012). Group three is significantly different from $G 2$ and G1in number of RGCs $\mathrm{P}<0.01$. Group 2 is significantly different from G1 $\mathrm{P}<0.01$ (Table 2, Figure 13).

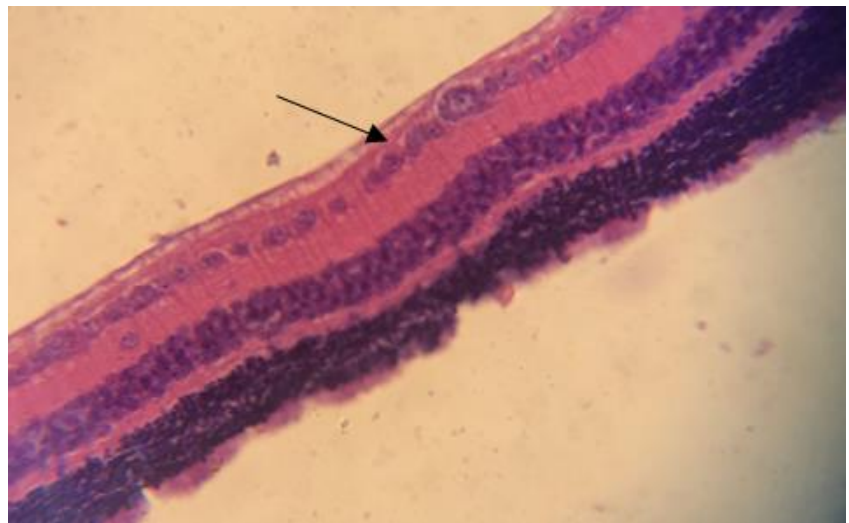

Figure 10: Micrograph of normal retina of G1, appeared normal retinal ganglionic cells (black arrow) (40X).H\&E stain.

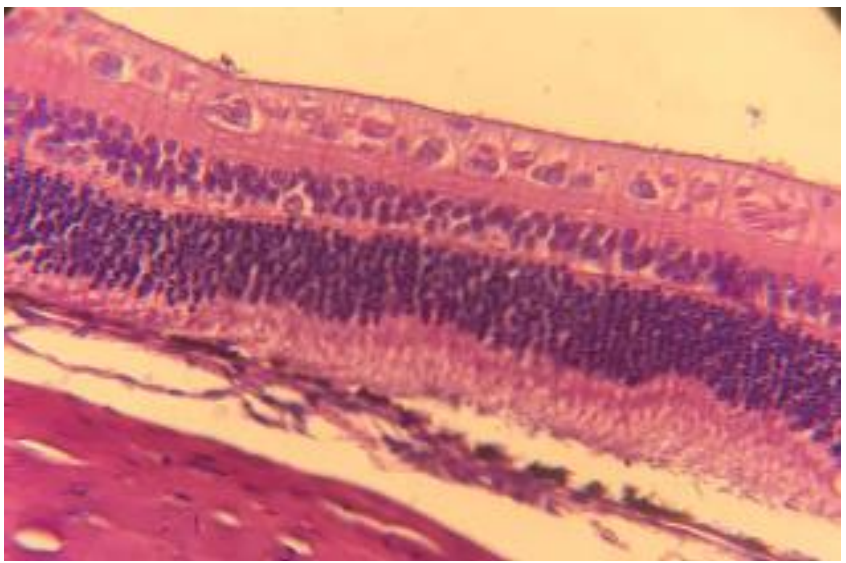

Figure 11: Micrograph of retina in G2 after two weeks from induction of glaucoma. (40X). H\&E stain.

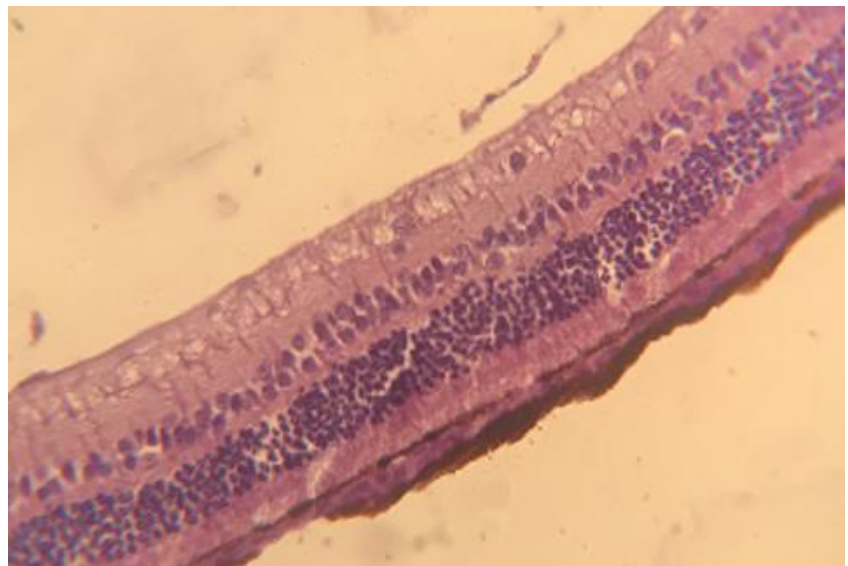

Figure 12: Micrograph of retina in G3 after two weeks from induction of glaucoma, (40X). H\&E stain.

Table 2: The means, SE and SD of number of retinal ganglionic cells

\begin{tabular}{lcc}
\hline Group & Mean & Std. Error \\
\hline G1 & 35.6667 & 0.66667 \\
G2 & $20.0000 *$ & 1.0000 \\
G3 & $3.0000 *$ & 0.11547 \\
\hline
\end{tabular}

\section{Optic nerve}

In normal optic nerve in G1 there was no vaculation and obvious orientation of nerve fibers (Figure 14). Optic nerve histology in G2 shown cells vaculation and constriction of blood vessels (Figure 15). There was increased of vacuolation, congested blood vessels, decreased quantity of schwann cells, segmental demyelination and low orientation of nerve fibers in G3 (Figure 16). 


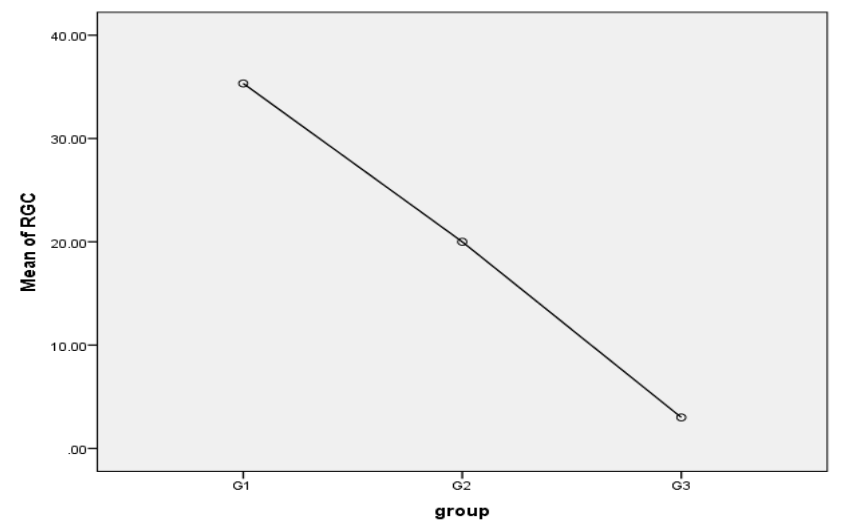

Figure 13: Diagram of means of RGC number, G3 display the lowest number of RGC among all groups.

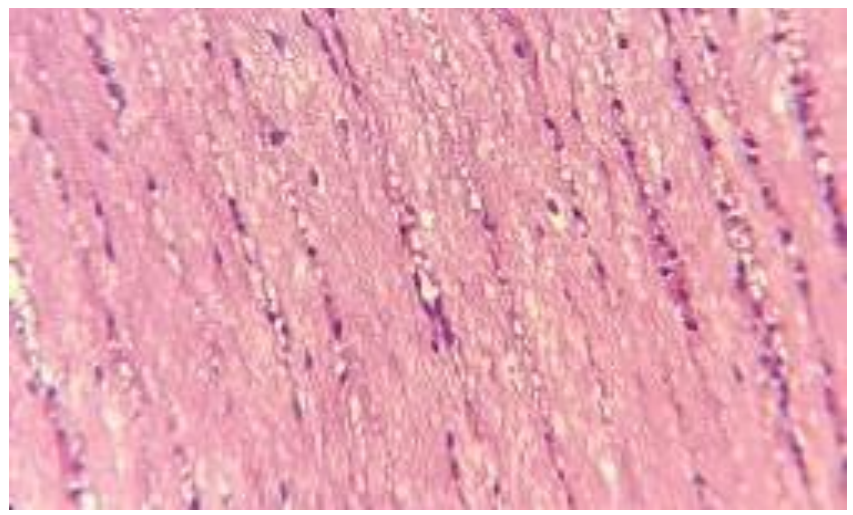

Figure 14: Micrograph of the longitudinal section of normal optic nerve. Normal myelination of nerve fibers, there is no Wallerian degeneration and good orientation of nerve fibers, (40X). H\&E stain.

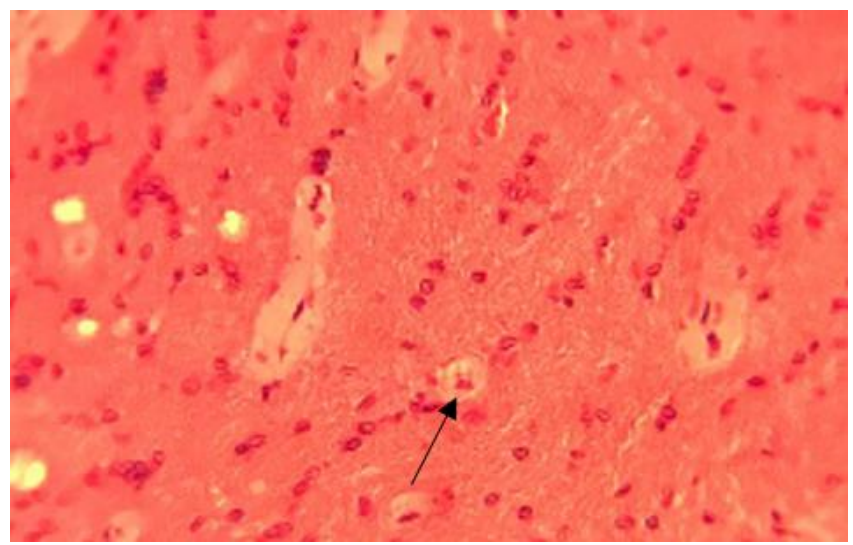

Figure 15: Micrograph of longitudinal section of optic nerve histology of G2 after two weeks from induction of glaucoma, there is vacuolation (black arrow) and disarrangement of optic nerve fibers (40X). H\&E stain.

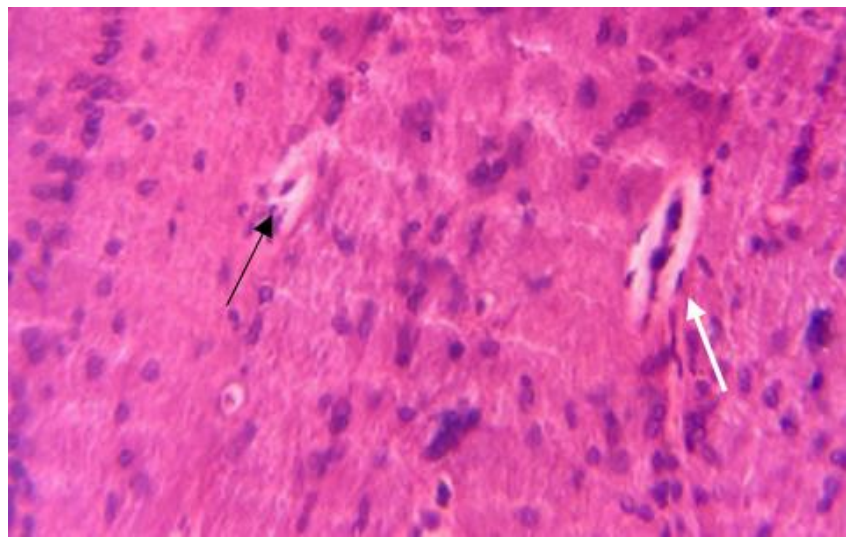

Figure 16: Micrograph of the longitudinal section of optic nerve histology of G3 after 2 weeks fom induction of glaucoma established low concentration of Schwann cells, congested blood vessel (white arrow), vacuolated degenerative nerve fibers (black arrow) and segmental demyelination (40X). H\&E stain.

\section{Discussion}

Trypsin is a proteolytic enzyme (10) the main role of this substance was harnessed for digestion and get debris to stop or decrease aqueous out flow. Alpha chymotrypsin which is a sub type of trypsin was used by (7) for induction of glaucoma in rabbit model.

Tonometry results of G2 displayed elevation of intraocular pressure in one animal while in G3 all animals had increase of IOP and this occur due to lysis of trabeculi that obstruct the drainage path way of the aqueous humor.

The concentration of trypsin used in G2 was inadequate to get the proper lysis to block the out flow of aqueous fluid.

The sudden and progress increased of intraocular pressure accompanied with different changes in the eye structures that was noticed clinically include displacement of lens increase of anterior chamber depth (ACD).

Increased IOP cause expansion of eye ball and scleral stretching that result in posterior luxation of lens and this sequel was confirmed by (11). Edema of cornea resulted from increased intraocular pressure that caused damaging of endothelium layer which is responsible of absorbance of water to the cornea. (12).

Ended with formation of keratoglobus which is limbus to limbus thinning of cornea. (13) this result agreed with (7) who documented displacement of lens due to extreme elevation of intraocular pressure so that increase of ACD. (14) reported enlargement of ACD and thin walled cornea in animals with chronic elevation of intraocular pressure after injection of autologous fixed red blood cells in to the anterior chamber.

While (15) did not report displacement of lens or increase in ACD when $0.1 \mathrm{ml}$ of $0.3 \%$ carbomer injected into the anterior chamber resulted in increase of intraocular pressure 
in eleven of twelve eyes with intraocular pressure mean 29$35 \mathrm{mmHg}$ extended from 20-50 days.

Trypsin enzyme that digest protein resulted in flexible cornea which is the main factor that effect on tonometry reading according to study by $(16,17)$ and this responsible of false negative readings of IOP in the first week in most rabbits in G3.

Histological findings presented loss and decreased number of retinal ganglionic cells (RGCs) in G 2 with $43.8 \%$ while in G3 the decrease of RGCs was $91.5 \%$ in compare with G1 due to increased intraocular pressure that cause mechanical compression which inhibit axonal transport resulted in enhancement of calcium influx in to the cells terminated with death of ganglion cells and this assured by (18).

This disagree with study by (4) they demonstrated $20 \%$ loss of RGCs after two weeks from induction of glaucoma by occlusion episcleral veins in mouse model. (19) whom reported $20 \%$ loss of axons when polystyrene microbeads injected into the anterior chamber in mice and rat model resulted in elevation of intraocular pressure up to 2 weeks and the prolonged elevation of intra ocular pressure up to (45 weeks) made this loss of axons. While (20) revealed the weekly injection of microspheres with hudroxypyl methylcellulose in to anterior chamber until 30-week period resulted in $30 \%$ loss of RGC.

\section{Conclusion}

Using of $0.2 \mathrm{ml}$ of $0.05 \%$ trypsin is the proper dose for induction of glaucoma which resulted in constant increased of intraocular pressure with degenerative changes of retina and optic nerve with in two weeks.

\section{Acknowledgments}

We are grateful to the College of Veterinary Medicine/University of Baghdad for providing the required materials for the research, as well as a suitable location and circumstances for the animals to be housed.

\section{Conflicts of interest}

We declare that there are no conflicts of interest regarding the publication of this manuscript.

\section{References}

1. Quigley HA andBroman AT. The number of the people with glaucoma worldwide in 2010 and 2020. Br J Ophthalmol. 2006;90:262-267.DOI: 10.1136/bjo.2005.081224

2. Chauhan BC, Pan J, Archibald ML, Levatte TL, Kelly ME, Tremlay F. Effect of intraocular pressure on optic disc topography, electro retinography, and axonal loss in a chronic pressure- induced rat model of optic nerve damage. Invest Ophthalmol Vis Sci .2002; 43: 2969-76. [available at]
3. Ahn, SJ, Hong, HK, Na, Y M, Park, S J, Ahn, J, Oh, J, Chung, J Y, Park, KH, Woo, S J. Use of Rabbit Eyes in Pharmacokinetic Studies of Intraocular Drugs. J Vis Exp. 2016;23: 53878. DOI: 10.3791/53878

4. Ederra JR, Verkman AS. Mouse model of sustained elevation in intraocular pressure produced by episcleral vein occlusion. Exp Eye Res. 2006; 82:879-884. DOI: .10.1016/j.exer.2005.10.019

5. Zhao D, Nguyen CT, Wong VH, Lim JK, He Z, Jobling AI, Fletcher EL, Chinnery HR, Vingrys AJ, Bui BV. Characterization of the Circumlimbal Suture Model of Chronic IOP Elevation in Mice and Assessment of Changes in Gene Expression of Stretch Sensitive Channels. Front Neurol Neurosci. 2017;11 :41. DOI: 10.3389/fnins.2017.00041

6. Gaassterland D, Kupfer C. Experimental glaucoma in the rhesus monkey. Invest Ophthalmol Vis Sci.1974;13: 455-457. [available at]

7. David S, Marvin S. Blood- aqueous barrier and alpha-chymotrypsin glaucoma in rabbits. Am J Ophhalmol.1974;77:379-383. DOI: $\underline{10.1016 / 0002-9394(74) 90744-2}$

8. Lipman NS, Marini RP, Erdman SE. A comparison of ketamine/xylazine and ketamine/xylazine/acepromazine anesthesia in the rabbit. Lab Anim Sci;40: 395-398. [available at]

9. Shariati A, Ameri H, Hinton DR, Humayun MS. The Effects of Davidson's Fixative Solution in Preserving the Rabbit Eye. Invest Ophthalmol Vis Sci. 2008;49: 5207. [available at]

10. Rawlings ND, Barrett AJ. Families of serine peptidases. Methods Enzymol. 1994; 244:19-61. DOI: 10.1016/0076-6879(94)44004-2

11. Leydolt C, Findl O, Drexeler W. Effect of changes in intraocular pressure on axial eye length and lens position, Eye.2008;22:657-661. [available at]s://doi.org/10.1038/sj.eye.6702709.

12. Bonanno JA. molecular mechanisms underlying the corneal endothelial pump. Exp Eye Res.2012;95: 2-7. DOI: 10.1016/j.exer.2011.06.004

13. Wallang BS, Das S. Kratoglobus.Eye.2013; 23: 1004-1012. [available atl

14. Quigley HA, Addicks EM. Chronic experimental glaucoma in primates. II. Effect of extended intraocular pressure elevation on optic nerve head and axonal transport. Invest Ophthalmol Vis Sci. 1980;19: 137-52. [available at]

15. Xu Y, Chen Z, Song J.A study of experimental carbomer glaucoma and other experimental glaucoma in rabbits. Chines J Ophthalmol.2002; 38(3): 172-5. [available at]

16. Liu J, Roberts CJ. Influence of corneal biomechanical properties on intraocular pressure measurement: quantitative analysis. J Cataract Refract Surg.2005;31: 146-155.DOI: 10.1016/j.jcrs.2004.09.031

17. Hamid HH, Taha AM. Anatomical and histological structure of the cornea in Sparrow hawk Accipiter nisus. Iraqi J Vet Sci. 2021; 35:437442. DOI: $10.33899 /$ ijvs.2020.126976.1424

18. Renu A, Gupta, Agarwal SK, Saxena P, Agrawal R, Shyam S. Current concepts in the pathophysiology of glaucoma. Indian $\mathbf{J}$ Ophthalmol.2009 ;57: 257-266.DOI: 10.4103/0301-4738.53049

19. Sappington RM, Carlson BJ, Crish SD, Calkins DJ. The microbead occlusion model: a paradigm for induced ocular hypertension in rats and mice. Invest Ophthalmol Vis Sci. 2010;51: 207-216. DOI: 10.1167/iovs.09-3947

20. Urcola JH, Hernandez M, Vecino E. Three experimental glaucoma models in rats: comparison of the effects of intraocular pressure elevation on retinal ganglion cell size and death. Exp eye Res.2006;83: 429-437. DOI: 10.1016/j.exer.2006.01.025 


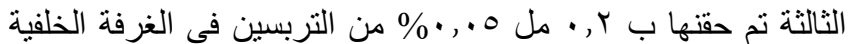

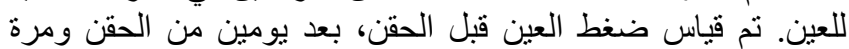

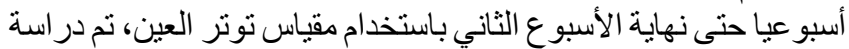

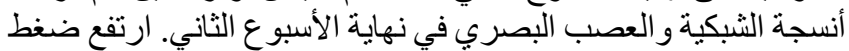

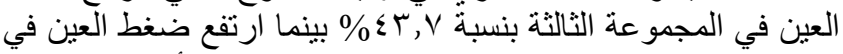

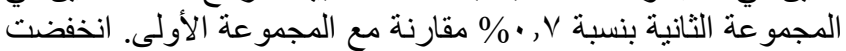

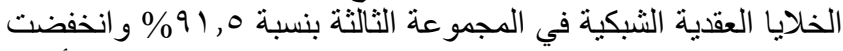

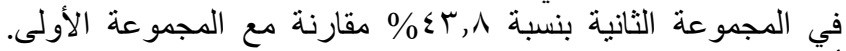

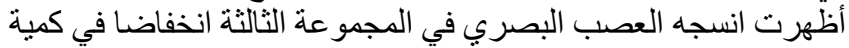

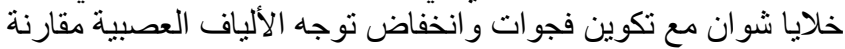

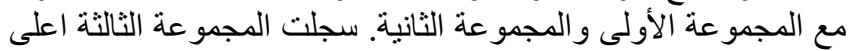

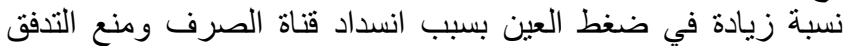

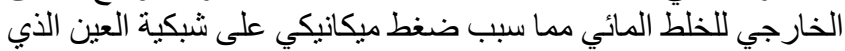

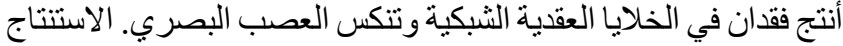

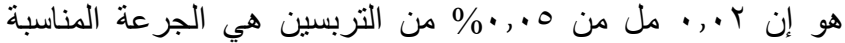

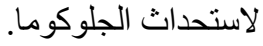

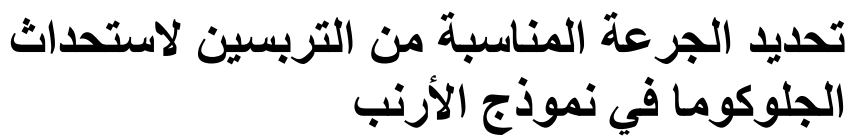

نور محمود محارب و حميد علي التميمي

فرع الجر احة والتوليد، كلية الطب البيطري، جامعة بغداد، بغداد، العر اق

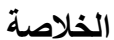

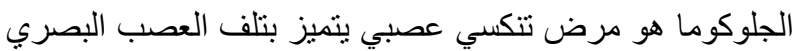

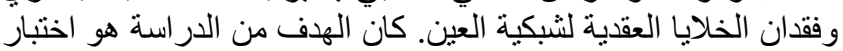

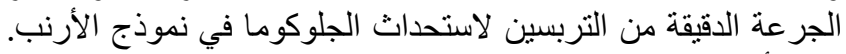

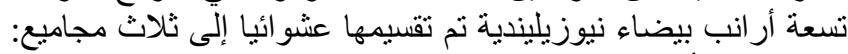

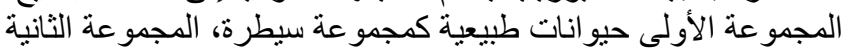

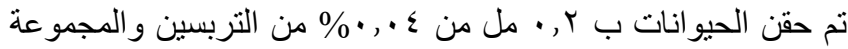

